\title{
Resting energy expenditure in elite athletes: development of new predictive equations based on anthropometric variables and bioelectrical impedance analysis derived phase angle
}

Maurizio Marra ${ }^{1 *+} \mathbb{D}$, Olivia Di Vincenzo ${ }^{1+}$, Iolanda Cioffi ${ }^{1}$, Rosa Sammarco ${ }^{1}$, Delia Morlino ${ }^{1}$ and Luca Scalfi ${ }^{2}$

\begin{abstract}
Background: An accurate estimation of athletes' energy needs is crucial in diet planning to improve sport performance and to maintain an appropriate body composition. This study aimed to develop and validate in elite athletes new equations for estimating resting energy expenditure (REE) based on anthropometric parameters as well as bioimpedance analysis (BIA)-derived raw variables and to validate the accuracy of selected predictive equations.

Methods: Adult elite athletes aged 18-40 yrs were studied. Anthropometry, indirect calorimetry and BIA were performed in all subjects. The new predictive equations were generated using different regression models. The accuracy of the new equations was assessed at the group level (bias) and at the individual level (precision accuracy), and then compared with the one of five equations used in the general population or three athletesspecific formulas.

Results: One-hundred and twenty-six male athletes (age $26.9 \pm 9.1 \mathrm{yrs}$; weight $71.3 \pm 10.9 \mathrm{~kg}$; BMl $22.8 \pm 2.7 \mathrm{~kg} / \mathrm{m}^{2}$ ) from different sport specialties were randomly assigned to the calibration $(n=75)$ or validation group $(n=51)$. REE was directly correlated with individual characteristics, except for age, and raw BIA variables. Most of the equations from the literature were reasonably accurate at the population level (bias within $\pm 5 \%$ ). The new equations showed a mean bias $-0.3 \%$ (Eq. A based on anthropometric parameters) and $-0.6 \%$ (Eq. B based on BIA-derived raw variables). Precision accuracy (individual predicted-measured differences within $\pm 5 \%$ ) was $\sim 75 \%$ in six out of eight of the selected equations and even higher for Eq. A (82.4\%) and Eq. B (92.2\%).

Conclusion: In elite athletes, BIA-derived phase angle is a significant predictor of REE. The new equations have a very good prediction accuracy at both group and individual levels. The use of phase angle as predictor of REE requires further research with respect to different sport specialties, training programs and training level.
\end{abstract}

Keywords: Athletes, Energy expenditure, Predictive equations, BIA, Phase angle, Accuracy

\footnotetext{
*Correspondence: marra@unina.it

${ }^{\dagger}$ Maurizio Marra and Olivia Di Vincenzo contributed equally to this work.

'Department of Clinical Medicine and Surgery, Federico II University of Naples, Via S. Pansini 5, 80138 Naples, Italy

Full list of author information is available at the end of the article
}

(c) The Author(s). 2021 Open Access This article is licensed under a Creative Commons Attribution 4.0 International License, which permits use, sharing, adaptation, distribution and reproduction in any medium or format, as long as you give appropriate credit to the original author(s) and the source, provide a link to the Creative Commons licence, and indicate if changes were made. The images or other third party material in this article are included in the article's Creative Commons licence, unless indicated otherwise in a credit line to the material. If material is not included in the article's Creative Commons licence and your intended use is not permitted by statutory regulation or exceeds the permitted use, you will need to obtain permission directly from the copyright holder. To view a copy of this licence, visit http://creativecommons.org/licenses/by/4.0/ The Creative Commons Public Domain Dedication waiver (http://creativecommons.org/publicdomain/zero/1.0/) applies to the data made available in this article, unless otherwise stated in a credit line to the data. 


\section{Background}

Total energy expenditure of most athletes is expected to be greater compared to general population because of training, and changes in metabolism and body composition [1]. At the same time, estimating energy needs is crucial in diet planning to improve sport performance and manage body mass in weight-category sports $[2,3]$. Further, under- or over-estimating athletes' energy requirements might result in unwanted changes in fat-free mass (FFM), and/or fat mass (FM), impaired performance and health concerns, for instance increased risk of injuries or cardiovascular diseases $[1,2,4]$.

Energy requirements may be assessed based on resting energy expenditure (REE) [5], which is the amount of energy expended at rest by a fasted individual in a thermoneutral environment, representing $60-70 \%$ of total energy expenditure in normal-weight healthy adults and variable percentages in athletes [6]. In human nutrition REE is commonly estimated by using predictive equations based on easily available variables such as age, stature, body weight, etc. Most of the widely used equations for estimating REE in the general population (Harris and Benedict (HB) [7], Schofield [8], FAO/WHO/UNU [9], Mifflin [10] and Owen [11]) have been developed based on minimally active or sedentary individuals. Taking into account different physical activity level and body composition (i.e. higher FFM and body cell mass with lower FM) relative to general population [12-14], the equation used for estimating REE in the general population may be not appropriate for athletic individuals. As a consequence, few specific predictive equations for REE have been developed for athletes, [15-18], indeed exhibiting some limitations. The study by De Lorenzo et al. included a small sample size $(n=51)$ [15] whereas the one by ten Haaf et al. involved recreational athletes exercising on average $9.1 \pm 5 \mathrm{~h}$ a week [17]. Wong et al. studied Asiatic athletes only [16] and Watson et al. [18] only females. Finally, Jagim et al. [5] determined the accuracy of selected predictive equations for REE, but they did not propose a validated formula.

REE is expected to be associated with FFM, which is a reasonable surrogate body composition marker for oxidatively active tissues [19]; in other word, FFM might be used for predicting REE, and from a practical point of view this is even more credible if field techniques are employed. In this perspective, bioelectrical impedance analysis (BIA) is widely used for assessing body composition in athletes [20], but the interpretation of BIA results depends to a large extent on the equation used to estimate FFM [21]. Interestingly, raw BIA variables such as bioimpedance index (BI-Index $=$ stature $^{2} /$ impedance at $50 \mathrm{kHz}$ ) and phase angle (PhA) might be taken into account as possible predictors of REE. In fact, while BIindex is strictly related to FFM, PhA is thought to be a proxy of both water distribution (i.e. the ratio between extracellular water-ECW and total body water-TBW) [22], body cell mass and cellular integrity [23]. So far, a relationship between REE and BI-index and/or PhA has already been observed in normal-weight or overweight subjects [24] as well as in patients with obesity [25] and Crohn's disease [26]. Not surprisingly, the results of these studies suggest that raw BIA variables may improve the prediction power under physiological conditions [24], but only to a limited extent in subjects with altered body water distribution [25, 26].

Based on this background, the primary aim of this study was to develop and validate new predictive equations of REE in elite athletes, considering not only anthropometric measures, but also raw BIA variables. The accuracy of new equations, as well as the one of selected predictive equations of REE used in the general population or in athletes, was evaluated at the group level (bias) and at the individual level (precision).

\section{Methods \\ Study design and subjects}

In the present study we have retrospectively analysed routine data collected between January 2012 and December 2019 in elite athletes defined as those who have previously competed as regional and/or national players [27].

Subjects were selected for this study according to the following inclusion criteria: (1) both sexes, (2) age between 18 and 45 yrs and (3) at least 24 h/week of training. Subjects affected by overt metabolic and/or endocrine diseases and/or regularly taking any medications or using any drugs affecting energy metabolism, were excluded. This study was conducted in accordance with the Declaration of Helsinki and was approved by the Federico II University Ethical Committee.

All measurements were performed early in the morning (8.30 a.m.) after an overnight fast (10-12 h) according to standardized conditions, i.e. abstention from alcohol, caffeine or other thermogenetic substances, smoking and any physical activity for $24 \mathrm{~h}$ (in most cases $36 \mathrm{~h}$ ) prior to the assessment.

\section{Anthropometry and bioelectrical impedance analysis}

Body weight was measured in duplicate to the nearest $0.1 \mathrm{~kg}$ using a platform beam scale and stature was measured in triplicate to the nearest $0.5 \mathrm{~cm}$ using a stadiometer (Seca 709; Seca Hamburg, Germany). The subject wore light clothes and no shoes. Body mass index (BMI) was calculated as body weight $(\mathrm{kg})$ divided by squared stature $\left(\mathrm{m}^{2}\right)$.

BIA was performed by phase-sensitive device (Human IM Touch, DS Medica S.r.l., Milan, Italy). Measurements were carried out with empty bladder, in a supine 
position for at least $10 \mathrm{~min}$ before starting the measurement). After cleaning skin surface, patients were asked to lay with upper and lower limbs slightly abducted, so there was no contact between the extremities and trunk. The measuring electrodes were placed on the anterior surface of the wrists and ankles, and the injecting electrodes were placed on the dorsal surface of the hands and the feet, respectively (overall, eight electrodes). Data for impedance and PhA from the non-dominant side of the body, measured at $50 \mathrm{kHz}$, were considered. BI-index was calculated as the ratio stature $/$ resistance $\left(\mathrm{cm}^{2} /\right.$ ohm).

Before each test the analyser was calibrated with the calibration considered successful if resistance value was between 382 and $385 \Omega$ and reactance was 44-46 $\Omega$, as indicated by the manufacturer guidelines. The test-retest coefficient of variation (CV) (as determined in ten subjects) was always less than $3 \%$.

\section{Resting energy expenditure}

REE was measured (MREE) by indirect calorimetry [28] using a canopy system (Vmax ${ }^{\bullet}$ Encore system, CareFusion Corporation, U.S.). The instrument was routinely checked by burning ethanol, whereas oxygen and carbon dioxide analysers were calibrated on the test day using nitrogen and standardized gases (mixtures of nitrogen, carbon dioxide and oxygen).

Measurement conditions for by indirect calorimetry were defined following the suggestions made by Compher et al. [29] and Fullmer et al. [30]. In addition to the standardized conditions already mentioned, REE was measured with the subject laying down, but awake, on a bed in a quiet environment. After a 15-min adaptation period, oxygen consumption and carbon dioxide production were measured for $45 \mathrm{~min}$. Only steady state periods of measurement were selected according to the procedures for the ventilated hood system $(<5 \% \mathrm{CV})$. The first $5 \mathrm{~min}$ were discarded. Also, the inter-day CV (as determined in 10 subjects on subsequent days) was always less than $4 \%$. The flow throughout the canopy was modified in order to maintain the $\mathrm{CO}_{2}$ between $0.6-0.8 \%$.

Energy expenditure was calculated using the abbreviated Weir's formula, neglecting protein oxidation [31]. Data were excluded from analysis if the respiratory quotient was outside the expected range $(0.71-1.00)$ and when measured REE was \pm 3 standard deviations outside the mean REE.

\section{Predictive equations}

In the validation group REE was predicted (PREE) using five equations that are widely mentioned with respect to the general population (Harris \& Benedict [7], Schofield [8], FAO/WHO/UNU [9], Mifflin [10] and Owen [11]), and three athletes-specific formulas from the literature
(De Lorenzo [15], Wong [16] and ten Haaf [17])(Table 1).

\section{Statistical analysis}

Statistical analyses were performed using IBM SPSS (version 26). All data are presented as mean \pm standard deviation (SD), unless otherwise specified, and significance was defined as $p<0.05$. The Kolmogorov-Smirnov Test and the Shapiro-Wilk Test were used to assess if variables were normally distributed.

As presented in Table 2, subjects were randomly assigned to either a calibration or a validation group.

As far as statistical power is concerned, in the calibration group for alpha level $=0.05$ and beta $=0.20$ a sample size of 75 subjects is requested to reach a $p<0.05$ for $r=0.330\left(R^{2}=0.10\right)$. In the validation group a sample size of 51 subjects is adequate to identify a significant between-groups difference of $50 \mathrm{kcal}$ with a standard deviation of $125 \mathrm{kcal}$.

Linear correlation was applied for evaluating associations between variables. Multivariate linear regression analysis was performed to develop the new predictive equations, with REE measured by indirect calorimetry as dependent variable. We generated models as follows: in Model 1, age, sex, weight, stature and BMI were set as predictors, while in Model 2 we added the raw BIA variables (BI-index and PhA). Coefficient of determination $\left(\mathrm{R}^{2}\right)$ and standard error of the estimate (SEE) were considered for assessing the predictive power of formulas. The regression equations, derived from the calibration subset, were applied to the validation group.

Differences between PREE and MREE as well as bias, i.e. the mean percent difference, were both used as a measure of accuracy at the population level. Bias was found acceptable if within $\pm 5 \%[32,33]$. The percentage of patients with a PREE within $90-110 \%$ of MREE was used as a measure of accuracy at the individual level (precision accuracy). Values lower than $90 \%$ were classified as underprediction, while values higher than $110 \%$ as overprediction. The root mean squared error (RMSE) was used to define the predictions obtained with these models. Finally, comparisons of PREE-MREE differences vs mean PREE-MREE values were performed by Bland and Altman plots to estimate the limits of agreement [34].

\section{Results}

One hundred and twenty-six male elite athletes from different sport specialties were included in the analysis. As mentioned above, data on anthropometric measures, raw BIA variables and MREE are reported for the calibration and validation groups in Table 2. Athletes from seven sports were recruited, practicing masters swimming $(n=$ $24,19 \%)$, cycling $(n=22,17.5 \%)$, running $(n=21,16.7 \%)$, 
Table 1 Resting energy expenditure predictive equations in their original unit (kcal/day, except Schofield and FAO/WHO/UNU (MJ/ day))

\begin{tabular}{ll}
\hline Equation & Formula \\
\hline Harris and Benedict [7] & Males $13.75 \times$ Weight $(\mathrm{kg})+5 \times$ Stature $(\mathrm{cm})-6.76 \times$ Age $(\mathrm{yrs})+66.47$ \\
Schofield [8] & Males $(18-30 \mathrm{yrs}) 63 \times$ Weight $(\mathrm{kg})-42 \times$ Stature $(\mathrm{m})+2953$ \\
& Males $(30-60 \mathrm{yrs}) 48 \times$ Weight $(\mathrm{kg})-11 \times$ Stature $(\mathrm{m})+3670$ \\
FAO/WHO/UNU [9] & Males $(18-30 \mathrm{yrs}) 15.3 \times$ Weight $(\mathrm{kg})-27 \times$ Stature $(\mathrm{m})+679$ \\
& Males $(30-60 \mathrm{yrs}) 11.6 \times$ Weight $(\mathrm{kg})-16 \times$ Stature $(\mathrm{m})+879$ \\
Mifflin [10] & $9.99 \times$ Weight $(\mathrm{kg})+6.25 \times$ Stature $(\mathrm{cm})-4.92 \times$ Age $(\mathrm{yrs})+166 \times$ Sex $(\mathrm{M}=1, \mathrm{~F}=0)-161$ \\
Owen [11] & Males $10.2 \times$ Weight $(\mathrm{kg})+879$ \\
De Lorenzo [15] & $9 \times$ Weight $(\mathrm{kg})+11.7 \times$ Stature $(\mathrm{cm})-857$ \\
Wong [16] & $13 \times$ Weight $(\mathrm{kg})+192 \times$ Sex $(\mathrm{M}=1, \mathrm{~F}=0)+669$ \\
Ten Haaf [17] & $11.936 \times$ Weight $(\mathrm{kg})+587.728 \times$ Stature $(\mathrm{cm})-8.129 \times$ Age $(\mathrm{yrs})+191.027 \times$ Sex $(\mathrm{M}=1, \mathrm{~F}=0)+29.279$ \\
\hline
\end{tabular}

karate $(n=17,13.5 \%)$, water polo $(n=16,12.7 \%)$, ballet dance $(n=15,11.9 \%)$ and boxing $(n=11,8.7 \%)$. Individual characteristics for each sport specialty are reported in Table 3. BMI was the highest in water polo players $\left(25.9 \pm 1.8 \mathrm{~kg} / \mathrm{m}^{2}\right)$ and the lowest in runners $(20.6 \pm 1.2$ $\mathrm{kg} / \mathrm{m}^{2}$ ). MREE was the highest in water polo players $(2195 \pm 244 \mathrm{~kg} /$ day $)$ and the lowest in ballet dancers $(1567 \pm 107 \mathrm{~kg} /$ day $)$ in line with the differences in body weight. Mean value of $\mathrm{PhA}$ varied between $8.57 \pm 0.65$ degrees in boxers and $6.96 \pm 0.54$ degrees in master swimmers, being higher in boxers, cyclists and water polo players (Table 3).

\section{Developing new predictive equations}

Linear correlations showed that MREE of the athletes directly correlated with individual characteristics and raw BIA variables, except for age $(r=-0.124, p=0.290)$. Actually, a strong correlation was found between MREE and body weight $(r=0.768, p<0.001)$, followed by BMI $(r=0.623, p<0.001)$, BI-index $(r=0.606, p<0.001)$ as an index of FFM, stature $(r=0.489, p<0.001)$ and PhA $(r=0.327, p=0.004)$.
Then, multiple regression analysis was performed to assess the relationship between MREE and different sets of potential predictors. Basic anthropometric measures (weight, stature and BMI) and age (although not significant in bivariate analysis) were considered first in Model 1 to generate the following Eq. A:

\begin{tabular}{llll}
\hline REE $(\mathrm{kcal} /$ day $)=$ & $17.2 \times$ Weight $(\mathrm{kg})$ & $-5.95 \times$ Age $(\mathrm{yrs})$ & +748 \\
$(1.5)$ & $(1.9)$ & $(117.9)$ \\
0.794 & -0.218 & \\
\hline
\end{tabular}

(unstandardized regression coefficients with SE in brackets and beta coefficients in italics)

$$
R^{2}=0.637 ; \mathrm{SEE}=150 \mathrm{kcal} / \text { day. }
$$

When raw BIA variables (BI-index and PhA) were added to the Model 2, PhA was included whereas age was excluded from the model, developing the following Eq. B:

\begin{tabular}{llll}
\hline REE $(\mathrm{kcal} /$ day $)=$ & $16.3 \times$ Weight $(\mathrm{kg})$ & $+95.4 \times \mathrm{PhA}$ (degrees) & -93 \\
$(1.5)$ & $(22)$ & $(197)$ \\
0.755 & 0.291 & \\
\hline
\end{tabular}

Table 2 Characteristics of the study sample for the calibration and validation groups

\begin{tabular}{llll}
\hline & $\begin{array}{l}\text { All } \\
(\boldsymbol{n}=\mathbf{1 2 6})\end{array}$ & $\begin{array}{l}\text { Calibration group } \\
(\boldsymbol{n}=\mathbf{7 5})\end{array}$ & $\begin{array}{l}\text { Validation group } \\
(\boldsymbol{n}=\mathbf{5 1 )}\end{array}$ \\
\hline Age, yrs & $26.9 \pm 9.1$ & $26.8 \pm 9.0$ & $27.1 \pm 9.5$ \\
Weight, kg & $71.3 \pm 10.9$ & $71.4 \pm 11.3$ & $71.1 \pm 10.6$ \\
Stature, cm & $177 \pm 7$ & $177 \pm 7$ & $177 \pm 7$ \\
$\mathrm{BMl}, \mathrm{kg} / \mathrm{m}^{2}$ & $22.8 \pm 2.7$ & $22.8 \pm 2.8$ & $22.8 \pm 2.6$ \\
MREE, kcal/die & $1831 \pm 250$ & $1834 \pm 261$ & $1826 \pm 234$ \\
$\mathrm{RQ}$ & $0.821 \pm 0.07$ & $0.832 \pm 0.07$ & $0.822 \pm 0.07$ \\
$\mathrm{Bl}$-index, $\mathrm{cm}^{2} / \Omega$ & $65.9 \pm 9.6$ & $65.9 \pm 9.8$ & $66.0 \pm 9.4$ \\
$\mathrm{PhA}$, degrees & $7.76 \pm 0.76$ & $7.79 \pm 0.74$ & $7.73 \pm 0.78$ \\
\hline
\end{tabular}

Data are expressed as mean \pm standard deviation

$B M I$ body mass index, $M R E E$ measured resting energy expenditure, $R Q$ respiratory quotient, $B l$-index bioimpedance index, $P h A$ phase angle 
Table 3 Characteristics of the study sample according to sport specialty

\begin{tabular}{|c|c|c|c|c|c|c|c|}
\hline & $\begin{array}{l}\text { Cycling } \\
(n=22)\end{array}$ & $(n=16)$ & $\begin{array}{l}\text { Masters } \\
\text { swimming } \\
(n=24)\end{array}$ & $(n=17)$ & $(n=15)$ & $(n=11)$ & $(n=21)$ \\
\hline $\begin{array}{l}\text { Age } \\
\text { (yrs) }\end{array}$ & $27.0 \pm 2.7^{\text {cdef }}$ & $24.2 \pm 6.6^{c}$ & $40.4 \pm 4.5^{\text {abdefg }}$ & $18.8 \pm 2.7^{\text {aceg }}$ & $19.1 \pm 1.1^{\text {acg }}$ & $20.7 \pm 2.7^{\text {aeg }}$ & $29.0 \pm 9.9^{\text {cdf }}$ \\
\hline $\begin{array}{l}\text { Weight } \\
(\mathrm{kg})\end{array}$ & $69.2 \pm 5.2^{\mathrm{bcg}}$ & $88.8 \pm 4.9^{\text {acdefg }}$ & $76.6 \pm 10.0^{\text {abdeg }}$ & $69.5 \pm 10.4^{\mathrm{bcg}}$ & $64.1 \pm 5.2^{\mathrm{bc}}$ & $70.0 \pm 5.2^{\mathrm{bg}}$ & $61.1 \pm 6.3^{\mathrm{abcdg}}$ \\
\hline $\begin{array}{l}\text { Stature } \\
(\mathrm{cm})\end{array}$ & $181 \pm 6^{\text {defg }}$ & $185 \pm 3^{\text {cdefg }}$ & $176 \pm 5^{\mathrm{bf}}$ & $176 \pm 7^{\mathrm{ab}}$ & $175 \pm 4^{\mathrm{ab}}$ & $169 \pm 5^{a b c}$ & $172 \pm 5^{\mathrm{ab}}$ \\
\hline $\begin{array}{l}\text { BMl } \\
\left(\mathrm{kg} / \mathrm{m}^{2}\right)\end{array}$ & $21.2 \pm 1.3^{\mathrm{bcf}}$ & $25.9 \pm 1.8^{\text {adeg }}$ & $24.6 \pm 2.8^{\text {adeg }}$ & $22.5 \pm 2.7^{\mathrm{bcg}}$ & $20.9 \pm 0.9^{\mathrm{bcf}}$ & $24.7 \pm 0.6^{\text {aeg }}$ & $20.6 \pm 1.2^{\mathrm{bcdf}}$ \\
\hline $\begin{array}{l}\text { MREE } \\
\text { (kcal/die) }\end{array}$ & $1866 \pm 142^{\text {beg }}$ & $2195 \pm 244^{\text {acdefg }}$ & $1766 \pm 188^{\text {bde }}$ & $1928 \pm 207^{\text {bceg }}$ & $1567 \pm 107^{\mathrm{abcdf}}$ & $1946 \pm 127^{\text {beg }}$ & $1641 \pm 120^{\mathrm{abdf}}$ \\
\hline$R Q$ & $0.785 \pm 0.031^{\text {beg }}$ & $0.865 \pm 0.046^{a}$ & $0.815 \pm 0.081$ & $0.804 \pm 0.049^{9}$ & $0.850 \pm 0.049^{a}$ & $0.807 \pm 0.082$ & $0.870 \pm 0.070^{\mathrm{ad}}$ \\
\hline $\begin{array}{l}\text { Bl-index } \\
\left(\mathrm{cm}^{2} / \Omega\right)\end{array}$ & $65.4 \pm 8.0^{\mathrm{bg}}$ & $78.8 \pm 8.3^{\text {acdefg }}$ & $67.6 \pm 7.7^{\mathrm{bg}}$ & $64.0 \pm 8.7^{\mathrm{bg}}$ & $67.7 \pm 6.3^{\mathrm{bg}}$ & $65.9 \pm 5.7^{\mathrm{bg}}$ & $55.2 \pm 5.0^{\text {abcdef }}$ \\
\hline $\begin{array}{l}\text { PhA } \\
\text { (degrees) }\end{array}$ & $8.31 \pm 0.79^{\text {cdg }}$ & $8.11 \pm 0.49^{c}$ & $6.96 \pm 0.54^{\mathrm{abdefg}}$ & $7.59 \pm 0.60^{\text {acf }}$ & $7.75 \pm 0.53^{c f}$ & $8.57 \pm 0.65^{\text {cdeg }}$ & $7.60 \pm 0.38^{\text {acf }}$ \\
\hline
\end{tabular}

Data are expressed as mean \pm standard deviation.

$B M I$ body mass index, MREE measured resting energy expenditure, $R Q$ respiratory quotient, $B l$-index bioimpedance index, $P h A$ phase angle.

${ }^{a}$ cycling; ${ }^{b}$ water polo; ${ }^{c}$ master swimming; ${ }^{d}$ karate; ${ }^{e}$ ballet dance; ${ }^{f}$ boxing; ${ }^{g}$ running

$p<0.05$

(unstandardized regression coefficients with SE in brackets, and beta coefficients in italics)

$$
R^{2}=0.675 ; \mathrm{SEE}=141 \mathrm{kcal} / \mathrm{d} \text {. }
$$

\section{Validation of predictive equations}

To assess the accuracy of the new predictive equations, as well as of those selected from the literature, 51 athletes were randomly assigned to the validation group. Prediction accuracy at the population level was evaluated by PREE-MREE difference, mean bias and RMSE in kcal/day (Table 4).

The new developed predictive formulas showed a mean bias < 1\% (Eq. A-0.3\%; Eq. B-0.6\%) with the lowest RMSE values of $88 \mathrm{kcal}$ (Eq. A) and $76 \mathrm{kcal}$ (Eq. B); while REE seemed to be underestimated by most of the other equations, with the exception of those by De Lorenzo and ten Haaf (Table 4). Overall, the PREEMREE difference was $<100 \mathrm{kcal} /$ day for the $\mathrm{HB}, \mathrm{FAO}$, Schofield, De Lorenzo, Wong and ten Haaf equations. The mean bias was as follows: $\mathrm{HB}-3.9 \%$; Schofield + 4.4\%; FAO - 4.4\%; De Lorenzo + 2\%; Wong $-1.4 \%$ and ten Haaf $+4 \%)$, and greater for the Mifflin $(-7 \%)$ and Owen $(-11.3 \%)$ equations.

(As shown in Fig. 1) the precision accuracy at the individual level (percentage of athletes with a PREE within $\pm 10 \%$ of MREE) was higher for the new equations (Eq. A $82.4 \%$, Eq. B 92.2\%) compared to those selected from the literature $(\sim 45 \%$ for the Owen, $\sim 65 \%$ for the Mifflin and $\sim 75 \%$ for the Harris-Benedict, FAO, Schofield, De Lorenzo, Wong and ten Haaf equations).

\section{Bland-Altman plots of PREE-MREE differences}

Lastly, the Bland-Altman method was used to quantify the agreement between PREE and MREE. Figure 2 shows that the best agreement was found for the new formulas. For the other equations, the $95 \%$ limits of agreement were wider $(+/-200-300 \mathrm{kcal} / \mathrm{d})$ with the largest values observed for the Mifflin and Owen equations.

Table 4 Evaluation of new and selected predictive equations in athletes (validation group)

\begin{tabular}{llll}
\hline REE predictive equations & $\begin{array}{l}\text { Difference } \\
\text { PREE-MREE } \\
\text { kcal/d Mean (SD) }\end{array}$ & Bias $^{\boldsymbol{s}_{3} \%}$ & $\begin{array}{l}\text { RMSE } \\
\text { kcal/d }\end{array}$ \\
\hline $\begin{array}{llll}\text { Equations for normal-weight subjects } \\
\text { HB }\end{array}$ & $-82(146)^{*}$ & -3.9 & 107 \\
Schofield & $-93(142)^{*}$ & -4.4 & 108 \\
FAO/WHO/UNU & $-92(140)^{*}$ & -4.4 & 107 \\
Mifflin & $-141(156)^{*}$ & -7.0 & 164 \\
Owen & $-222(140)^{*}$ & -11.3 & 225 \\
Equations for athletes & & & \\
De Lorenzo & $21(173)$ & 2 & 94 \\
Wong & $-41(153)^{*}$ & -1.4 & 104 \\
Ten Haaf & $60(152)^{*}$ & 4 & 98 \\
Equation A & $-17(134)$ & -0.3 & 88 \\
Equation B & $-20(124)$ & -0.6 & 76 \\
\hline
\end{tabular}

Average REE measured with indirect calorimetry $=1826 \pm 234 \mathrm{kcal} / \mathrm{d}$ REE resting energy expenditure, MREE measured resting energy expenditure, PREE predicted resting energy expenditure, RMSE root mean square error, $H B$ Harris and Benedict, FAO Food and Agriculture Organization

${ }^{\S}$ Mean percentage error between predicted and measured REE; * $p<0.05$ 


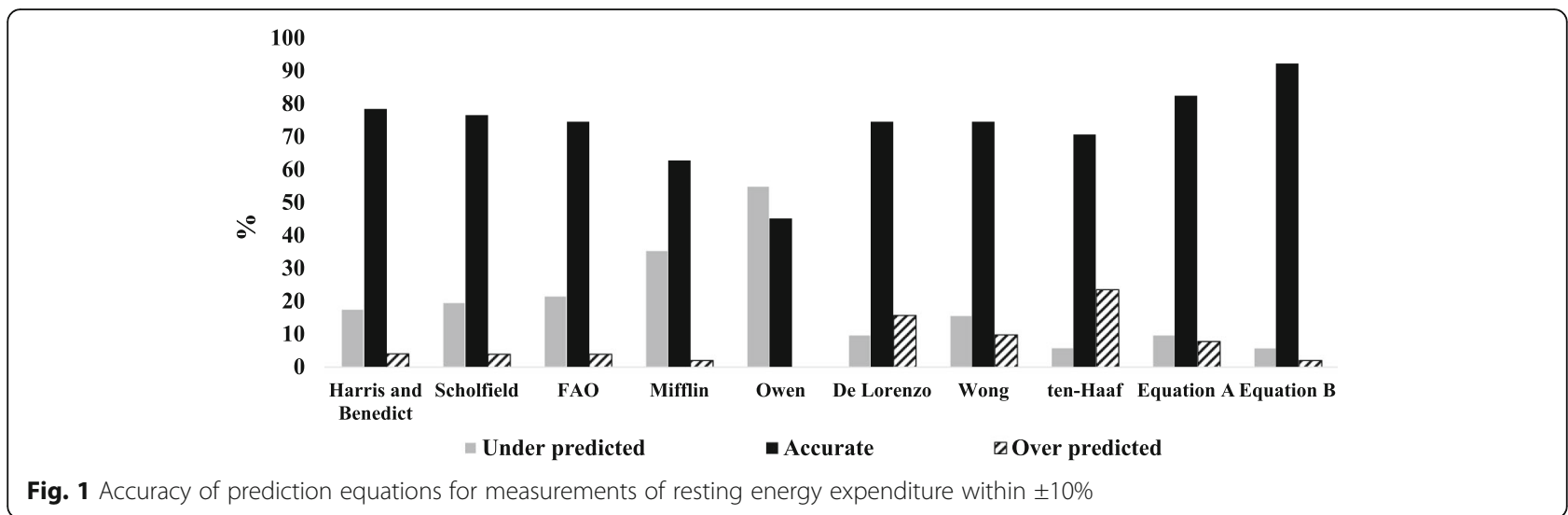

\section{Discussion}

The primary purpose of this study was to develop and cross-validate new equations for estimating REE in a group of elite male athletes of different sport specialties, and then to compare them with existing formulas. The new equations provide the best prediction of REE in the validation group, with the use of BIA-derived $\mathrm{PhA}$ significantly improving the prediction power of the equation.

Meeting energy requirements is a priority of athletes. Inadequate energy intake might compromises performance and reduces the benefits of training $[1,2]$. Energy needs are usually estimated by REE multiplied by the appropriate activity factor. To date, only a few number of predictive equations for REE have been specifically developed for athletes [15-18]. De Lorenzo formula [15] was derived in a sample of 51 male athletes (22 water polo, 12 judo, 17 karate) who exercised at least $3 \mathrm{~h} /$ day; in that paper REE was underestimated by most of the seven equations selected from the literature. Later, Wong et al. [16] proposed sex-specific predictive formulas for elite Malaysian athletes in most cases practicing combat sports. Of note, Malaysian population seemed to have relatively low body frames and size and, therefore, low REE [16]. They found that mean resting energy expenditure measured by indirect calorimetry were similar in males to values predicted using the $\mathrm{HB}$ [7], FAO [9] and De Lorenzo [15] equations; indeed the accuracy of the predictive formulas was not evaluated. Also, ten Haaf et al. [17] developed two predictive equations for recreational athletes practicing $>3 \mathrm{~h}$ /day two times a week, the first formula being based on weight, the second one on FFM (determined using pletismography). Authors pointed out that the weight-based equation had a higher precision accuracy (83\% for males) compared to the De Lorenzo formula (77.4\% for males). Finally, Watson et al. [18] derived two formulas in a sample of 66 collegiate female athletes from eleven different sports; the first equation was based on weight, the second one on FFM (estimated by skinfold thickness). Authors stated that both equations were more accurate for resting metabolic rate estimation in their population but did not evaluate bias or precision accuracy. Jagim et al. [5] did not derive new formulas but determined the accuracy of several predictive equations for REE in both male and female athletes; most of the five equations selected from the literature underestimated REE in both sexes. Of the previous studies, only the one by Watson

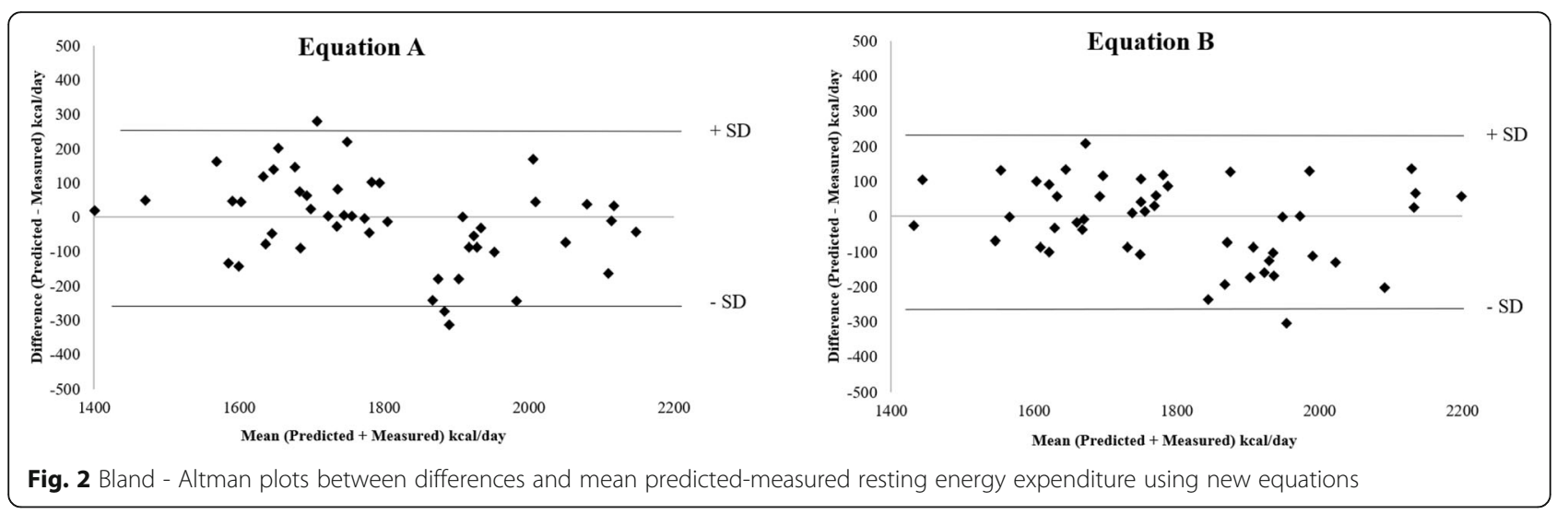


et al. [18] described the relationships between REE and age or different anthropometric variables, showing that age was not related to REE while the best predictor was body weight $(r=0.590)$. These results are confirmed in our study since body weight was the best predictor $(r=$ 0.768 ) while there was no association with age. Some authors also introduced FFM as predictor, with no increase in the prediction power $[17,18]$.

In the present study, first we developed an equation based on age and main anthropometric variables (weight, stature, and BMI) (Model 1, Eq. A). In addition to age, weight emerged as the only significant predictor. Two of the existing formulas for athletes identified also stature as predictor $[15,17]$ while in the athletes we studied, REE was correlated to stature in univariate analysis, but not in multiple regression analysis, $p=$ 0.374).

Instead of using BIA-derived body composition (strictly dependent on the BIA formula used), we opted for including raw BIA variables (BI-index and $\mathrm{PhA}$ ) in the regression model (Model 2, Eq. B).

BI-index is directly related to FFM and quite always included as predictor in the BIA equations to predict FFM. More recently, attention has been focused on the role of PhA as a biomarker of body cell mass and muscle quality as well as of water distribution (ratio between extracellular water-ECW and intracellular water-ICW) [22]. Thus, high PhA indicates greater cellularity (e.g. more body cell mass relative to FFM), cellular integrity and cell functions [22]. It may represent a proxy parameter of muscle quality in athletes, being significantly associated with physical activity and muscle strength $[35,36]$. A recent systematic review showed that PhA was higher in athletes vs controls whereas it was still uncertain to what extent PhA differs among various sports [37]. In addition, PhA may help in detecting low muscle quality and identifying sarcopenia [38]. In previous studies, we also found that both BI-index and $\mathrm{PhA}$ improved the prediction power of REE under physiological conditions [24]. The findings of the present paper confirmed that $\mathrm{PhA}$ was as a significant predictor along with weight, with $R^{2}$ increasing from 0.637 to 0.675 and SEE decreasing from 150 to $141 \mathrm{kcal} /$ day. On the contrary, BI-index was not recognized as a stronger predictor than weight, possibly because of low body fat percentage and low BMI. In general, for those with no access to BIA, only age and weight values are sufficient for predicting REE in male elite athletes.

As additional aim, we validated the two new equations and eight formulas selected from the literature (5 for the general population and 3 for athletes), at both population and individual level. On the average, the accuracy was very good for our new formulas, since bias ranged within $\pm 1 \%$. Similarly, most of the selected equations, except the Mifflin and Owen ones, showed an acceptable prediction accuracy (bias $\pm 5 \%$ ).

From a practical point of view, evaluating the accuracy of predictive equations at individual level (within $\pm 10 \%$ ) is crucial for the nutritional management of the single athlete. This study shows that precision was high for the new formulas, especially for Eq. B ( 92\%) including $\mathrm{PhA}$ in the model while it was lower, being close to $75 \%$, for most of the other formulas (with the exception of the Mifflin and Owen ones for which it was much lower). Looking at the Bland-Altman plots, most of the prediction equations were more accurate at lower ranges of MREE and less accurate with the higher REE values. The new formulas gave the narrowest limits of agreement and the lowest bias.

To the best of authors' knowledge, this is the first study that developed and cross-validate equations for elite athletes to predict REE based not only on anthropometric measures, but also on raw BIA variables. Overall, we conducted this study in a reasonable large sample of individuals, using recognized and well-documented methods and in line with similar previous studies in healthy subjects. Furthermore, the assessment of BIA with the same device has limited the device-related changes in PhA. Nevertheless, these findings are subject by a number of limitations. Since this is a retrospective study, our findings need to be confirmed in larger samples and in different sports disciplines. Additionally, we studied elite athletes mostly practicing endurance sports. Lastly, female athletes were excluded from the analysis due to the small number of potential participants $(n=$ 27 ); therefore, we have developed new athlete-specific predictive equations for estimating REE in elite male athletes only.

\section{Conclusions}

As main finding, in elite athletes BIA-derived PhA is a significant predictor of REE and improved the prediction power of the model. The new equations exhibited a very good accuracy at population level, while precision at the individual level was markedly higher compared to that reported by previous studies in the general population as well as athletes. However, the use of $\mathrm{PhA}$ as predictor of REE requires further research with respect to different sport specialties, training programs and training level.

\section{Abbreviations \\ BI-Index: Bioimpedance Index; BIA: Bioelectrical Impedance Analysis; BMI: Body Mass Index; ECW: Extracellular Water; FAO: Food and Agriculture Organization; FFM: Fat-Free Mass; FM: Fat Mass; HB: Harris and Benedict; ICW: Intracellular Water; MREE: Measured Resting Energy Expenditure; PhA: Phase Angle; PREE: Predicted Resting Energy Expenditure; REE: Resting Energy Expenditure; TBW: Total Body Water}

Acknowledgements

Not applicable. 


\section{Authors' contributions}

MM and ODV formulated the study concept and design. MM, ODV and RS acquired data used in the study and assisted in the interpretation of this data. MM, LS and ODV interpreted data, drafted the manuscript, and completed the data analysis and interpretation. IC, RS and DM helped advise the direction of the manuscript and made substantial revisions. Each author has read and approved the final manuscript prior to submission.

\section{Funding}

Not applicable.

\section{Availability of data and materials}

All data pertaining to the conclusions of the study are found within the article. The corresponding data set used is available under reasonable requests.

\section{Declarations}

\section{Ethics approval and consent to participate}

This study was conducted in accordance with the Declaration of Helsinki and was approved by the Federico II University Ethical Committee.

\section{Consent for publication}

Not applicable.

\section{Competing interests}

The authors declare that they have no competing interests.

\section{Author details}

${ }^{1}$ Department of Clinical Medicine and Surgery, Federico II University of Naples, Via S. Pansini 5, 80138 Naples, Italy. ${ }^{2}$ Department of Public Health, Federico II University of Naples, Via S. Pansini 5, 80138 Naples, Italy.

Received: 5 January 2021 Accepted: 4 October 2021

Published online: 26 October 2021

\section{References}

1. Thomas DT, Erdman KA, Burke LM. American College of Sports Medicine joint position statement. Nutrition and athletic performance. Med Sci Sports Exerc. 2016;48(3):543-68. https://doi.org/10.1249/MSS.0000000000000852.

2. Rodriguez NR, DiMarco NM. Langley S, American dietetic association, dietitians of Canada, American College of Sports Medicine: nutrition and athletic performance. Position of the American dietetic association, dietitians of Canada, and the American College of Sports Medicine: nutrition and athletic performance. J Am Diet Assoc. 2009;109(3):509-27. https://doi. org/10.1016/j.jada.2009.01.005.

3. Trexler ET, Smith-Ryan AE, Norton LE. Metabolic adaptation to weight loss: implications for the athlete. J Int Soc Sports Nutr. 2014;1 1(1):7. https://doi. org/10.1186/1550-2783-11-7.

4. Melin AK, Heikura IA, Tenforde A, Mountjoy M. Energy availability in athletics: health, performance, and physique. Int I Sport Nutr Exerc Metab. 2019;29(2):152-64. https://doi.org/10.1123/ijsnem.2018-0201.

5. Jagim AR, Camic CL, Kisiolek J, Luedke J, Erickson J, Jones MT, et al. Accuracy of resting metabolic rate prediction equations in athletes. J Strength Conditioning Res. 2018;32(7):1875-81. https://doi.org/10.1519/JSC. 0000000000002111.

6. Marra M, Montagnese C, Sammarco R, Amato V, Della Valle E, Franzese A, et al. Accuracy of Predictive Equations for Estimating Resting Energy Expenditure in Obese Adolescents. J Pediatr. 2015;166:1390-1396.e1.

7. Harris JA, Benedict FG. A biometric study of human basal metabolism. Proc Natl Acad Sci U S A. 1918;4(12):370-3. https://doi.org/10.1073/pnas.4.12.370.

8. Schofield WN. Predicting basal metabolic rate, new standards and review of previous work. Hum Nutr Clin Nutr. 1985;39(Suppl 1):5-41.

9. Energy and protein requirements. Report of a joint FAO/WHO/UNU Expert Consultation. World Health Organ Tech Rep Ser. 1985;724:1-206.

10. Mifflin MD, St Jeor ST, Hill LA, Scott BJ, Daugherty SA, Koh YO. A new predictive equation for resting energy expenditure in healthy individuals. Am J Clin Nutr. 1990;51(2):241-7. https://doi.org/10.1093/ajcn/51.2.241.

11. Owen OE, Holup JL, D’Alessio DA, Craig ES, Polansky M, Smalley KJ, et al. A reappraisal of the caloric requirements of men. Am J Clin Nutr. 1987:46(6): 875-85. https://doi.org/10.1093/ajcn/46.6.875.
12. Ribeyre J, Fellmann N, Montaurier C, Delaitre M, Vernet J, Coudert J, et al. Daily energy expenditure and its main components as measured by wholebody indirect calorimetry in athletic and non-athletic adolescents. Br J Nutr. 2000;83(4):355-62.

13. Poehlman ET, Melby CL, Badylak SF. Resting metabolic rate and postprandial thermogenesis in highly trained and untrained males. Am J Clin Nutr. 1988; 47(5):793-8. https://doi.org/10.1093/ajcn/47.5.793.

14. Melby CL, Schmidt WD, Corrigan D. Resting metabolic rate in weightcycling collegiate wrestlers compared with physically active, noncycling control subjects. Am J Clin Nutr. 1990;52(3):409-14. https://doi.org/10.1093/a $\mathrm{jcn} / 52.3 .409$.

15. De Lorenzo A, Bertini I, Candeloro N, Piccinelli R, Innocente I, Brancati A. A new predictive equation to calculate resting metabolic rate in athletes. J Sports Med Phys Fitness. 1999;39(3):213-9.

16. Wong JE, Poh BK, Shanita SN, Izham MM, Chan KQ, Tai MD, et al. Predicting basal metabolic rates in Malaysian adult elite athletes. Singapore Medical Journal. 2012;53:744-9.

17. ten Haaf T, Weijs PJM. Resting Energy Expenditure Prediction in Recreational Athletes of 18-35 Years: Confirmation of Cunningham Equation and an Improved Weight-Based Alternative. Alemany M, editor. PLoS One. 2014;9: e108460.

18. Watson AD, Zabriskie HA, Witherbee KE, Sulavik A, Gieske BT, Kerksick CM. Determining a resting metabolic rate prediction equation for collegiate female athletes. J Strength Conditioning Res. 2019;33(9):2426-32. https://doi. org/10.1519/JSC.0000000000002856.

19. Gallagher D, Visser M, Wang Z, Harris T, Pierson RN, Heymsfield SB. Metabolically active component of fat-free body mass: influences of age, adiposity, and gender. Metabolism. 1996;45(8):992-7. https://doi.org/10.101 6/S0026-0495(96)90269-3.

20. Campa F, Toselli S, Mazzilli M, Gobbo LA, Coratella G. Assessment of body composition in athletes: a narrative review of available methods with special reference to quantitative and qualitative bioimpedance analysis. Nutrients. 2021;13(5):1620. https://doi.org/10.3390/nu13051620.

21. Kyle UG, Bosaeus I, De Lorenzo AD, Deurenberg P, Elia M, Manuel Gómez J, et al. Bioelectrical impedance analysis-part II: utilization in clinical practice. Clin Nutr. 2004;23(6):1430-53. https://doi.org/10.1016/.cInu.2004.09.012.

22. Lukaski HC, Kyle UG, Kondrup J. Assessment of adult malnutrition and prognosis with bioelectrical impedance analysis: phase angle and impedance ratio. Curr Opin Clin Nutr Metab Care. 2017;20(5):330-9. https:// doi.org/10.1097/MCO.0000000000000387.

23. Norman K, Stobäus N, Pirlich M, Bosy-Westphal A. Bioelectrical phase angle and impedance vector analysis--clinical relevance and applicability of impedance parameters. Clin Nutr. 2012;31(6):854-61. https://doi.org/10.101 6/j.clnu.2012.05.008.

24. Marra M, Sammarco R, Cioffi I, Morlino D, Di Vincenzo O, Speranza E, Pasanisi $F$. New predictive equations for estimating resting energy expenditure in subjects with normal weight and overweight. Nutrition. 2021;84:111105. https://doi.org/10.1016/j.nut.2020.111105.

25. Marra M, Cioffi I, Sammarco R, Santarpia L, Contaldo F, Scalfi L, et al. Are raw $B I A$ variables useful for predicting resting energy expenditure in adults with obesity? Nutrients. 2019;11(2). https://doi.org/10.3390/nu11020216.

26. Marra M, Cioffi I, Morlino D, Vincenzo OD, Pagano MC, Imperatore $\mathrm{N}$, et al. New predictive equations for estimating resting energy expenditure in adults with Crohn's disease. J Parenter Enter Nutr. 2020;44(6):1021-8. https:// doi.org/10.1002/jpen.1790.

27. Swann C, Moran A, Piggott D. Defining elite athletes: issues in the study of expert performance in sport psychology. Psychol Sport Exerc. 2015;16:3-14. https://doi.org/10.1016/j.psychsport.2014.07.004.

28. Elia M, Livesey $\mathrm{G}$. Theory and validity of indirect calorimetry during net lipid synthesis. Am J Clin Nutr. 1988;47(4):591-607. https://doi.org/10.1093/ajcn/47.4.591.

29. Compher C, Frankenfield D, Keim N, Roth-Yousey L. Evidence analysis working group. Best practice methods to apply to measurement of resting metabolic rate in adults: a systematic review. J Am Diet Assoc. 2006;106(6): 881-903. https://doi.org/10.1016/j.jada.2006.02.009.

30. Fullmer S, Benson-Davies S, Earthman CP, Frankenfield DC, Gradwell E, Lee PSP, et al. Evidence analysis library review of best practices for performing indirect calorimetry in healthy and non-critically ill individuals. J Acad Nutr Diet. 2015;115:1417-1446.e2.

31. Weir JB de V. New methods for calculating metabolic rate with special reference to protein metabolism. J Physiol. 1949;109(1-2):1-9. https://doi. org/10.1113/jphysiol.1949.sp004363. 
32. Frankenfield DC, Rowe WA, Smith JS, Cooney RN. Validation of several established equations for resting metabolic rate in obese and nonobese people. J Am Diet Assoc. 2003;103(9):1152-9. https://doi.org/10.1016/500028223(03)00982-9.

33. Frankenfield D, Roth-Yousey L, Compher C. Comparison of predictive equations for resting metabolic rate in healthy nonobese and obese adults: a systematic review. J Am Diet Assoc. 2005;105(5):775-89. https://doi.org/1 0.1016/j.jada.2005.02.005.

34. Bland JM, Altman DG. Statistical methods for assessing agreement between two methods of clinical measurement. Lancet. 1986;1:307-10.

35. Di Vincenzo O, Marra M, Sammarco R, Speranza E, Cioffi I, Scalfi L. Body composition, segmental bioimpedance phase angle and muscular strength in professional volleyball players compared to a control group. J Sports Med Physical Fitness. 2020;6:870-4.

36. Marra M, Di Vincenzo O, Sammarco R, Morlino D, Scalfi L. Bioimpedance phase angle in elite male athletes: a segmental approach. Physiol Meas. 2020;12(12):125007. https://doi.org/10.1088/1361-6579/abcb5c.

37. Di Vincenzo O, Marra M, Scalfi L. Bioelectrical impedance phase angle in sport: a systematic review. J Int Soc Sports Nutr. 2019;16(1):49. https://doi. org/10.1186/s12970-019-0319-2

38. Di Vincenzo O, Marra M, Di Gregorio A, Pasanisi F, Scalfi L. Bioelectrical impedance analysis (BIA) -derived phase angle in sarcopenia: a systematic review. Clin Nutr. 2021;40(5):3052-61. https://doi.org/10.1016/j.clnu.2020.10 048.

\section{Publisher's Note}

Springer Nature remains neutral with regard to jurisdictional claims in published maps and institutional affiliations.

Ready to submit your research? Choose BMC and benefit from:

- fast, convenient online submission

- thorough peer review by experienced researchers in your field

- rapid publication on acceptance

- support for research data, including large and complex data types

- gold Open Access which fosters wider collaboration and increased citations

- maximum visibility for your research: over $100 \mathrm{M}$ website views per year

At BMC, research is always in progress.

Learn more biomedcentral.com/submissions 